\title{
Impact of Oral Zinc Supplementation on Glycemic Control in Type 2 Diabetic Patients: Single-blinded Randomized Controlled Trial
}

\section{Almass F Hassan', Maged S Khattab ${ }^{1}$, Abdelrauof M El Deib ${ }^{2}$, Hind M Salama ${ }^{1}$, Mohamed A Mohamed ${ }^{1}$, Hassan A Shora ${ }^{4 *}$ and Ismail Dahshan ${ }^{1}$}

${ }^{1}$ Family Medicine Department, Faculty of Medicine, Suez Canal University, Egypt

${ }^{2}$ Internal Medicine Department, Faculty of Medicine, Suez Canal University, Egypt

${ }^{3}$ Molecular Biology/Biochemistry, Faculty of Sciences, Port-Said University,

Port-Said, Egypt

${ }^{4}$ Senior Research Scientist, Head of Medicine \& Diabetes Center, Port-Said University

\& Ismailia Medical Complex, Egypt

*Corresponding Author: Hassan A Shora, Senior Research Scientist, Head of

Medicine \& Diabetes Center, Port-Said University \& Ismailia Medical Complex, Egypt,

E-mail: hassanshora56@gmail.com

DOI: $10.31080 /$ ASMS.2022.06.1142
Received: December 06, 2021

Published: December 20, 2021

(C) All rights are reserved by Hassan A Shora.,

et al.

\section{Abstract}

Objective: Type 2 diabetes mellitus is one of the world's most prevalent and fatal diseases. Zinc is involved in metabolism of glucose via its participation in insulin crystallization and signaling. This study aimed to evaluate the effect of zinc supplementation on glycemic control in type 2 diabetic patients.

Materials and Methods: The participants consisted of 200 type 2 diabetic patients attending the family medicine outpatient clinics in Suez Canal University who were randomly assigned into two groups, intervention, and control group. The study was approved by Ethics Committee of Suez canal University and all participant' consent was assured. This study was carried out between April 2019 and June 2019. The intervention group received oral capsule of zinc sulphate (25 mg) daily, the second control group was given placebo, identical for 12 weeks. outcome measures consisted mainly of Glycated haemoglobin (HbA1c \%) that was assessed at baseline and after 12 weeks. Follow up visits were conducted at the $4^{\text {th }}, 8^{\text {th }}$ and $12^{\text {th }}$ week from beginning of the study to check adherence to treatment every visit by interview and pill counts.

Results: Glycated haemoglobin (HbA1c \%) was significantly reduced in zinc group compared to placebo group (p = 0.008).

Conclusion: Zinc supplementation addition to routine management of adult type 2 diabetics on oral hypoglcemics only may improve glycemic control in this short single blinded randomized controlled trial.

Keywords: Type 2 Diabetes; Zinc Supplementation; Glycemic Control; Randomized Controlled Trial

\section{Introduction}

Type 2 diabetes mellitus is one of the world's most prevalent and fatal diseases. Type 2 diabetics represent $90 \%$ of all cases of diabetes. Recent reports illustrate advanced increases in its global prevalence. Two factors have been postulated as major reasons for this rapid increase in the global prevalence of diabetes, the in- creasingly unhealthy dietary habits, combined with lower levels of physical activity, and increasing obesity [1].

About 425 million adults were living with diabetes in 2017; by 2045 this will rise to 629 million. It was postulated that about $79 \%$ of adults with diabetes were living in middle and low-income countries [2]. The International Diabetes Federation (IDF) listed 
Egypt among the world top 10 countries in the number of patients with diabetes. It is expected that the number of patients with diabetes in the Middle East and North Africa (MENA) region to grow by $96 \%$ from year 2013 to 2035 or from 34.6 million to 67.9 million. In Egypt, the prevalence of diabetes is around 15.56\% among adults between 20 and 79 years of age, with an annual death of 86,478 related to diabetes [3].

Zinc is an essential trace element crucial for the function of more than 300 enzymes that are regulated by over two thousands transcription factors and it is important for cellular processes like cell division and apoptosis. Hence, the concentration of zinc in the human body is tightly regulated and disturbances of zinc homeostasis have been associated with several diseases including diabetes mellitus [4].

Zinc is involved in metabolism of glucose via its participation in insulin signaling, crystallization, storage and secretion. It is concentrated in the secretory vesicles of the beta-cells of the pancreas where it forms an integral component of the insulin structure to stabilize it and minimize its susceptibility to oxidative damage [5].

Whole-body level dysregulation of zinc is known to occur in both type 1 and type 2 diabetes. However, it remains unclear as to whether zinc deficiency causes the disease or is merely a consequence of the disease. A possible causal link between changes in zinc homeostasis and pancreatic $\beta$ cell function was suggested in 2007 with the identification of an association between the risk of T2DM and polymorphisms in the SLC30A8 gene, which encodes zinc transporter ZnT8 [6].

A defect in zinc homeostasis is reported in diabetic patients, including lower serum zinc concentrations and higher urinary zinc excretion as compared to healthy controls. Lower serum zinc in diabetics is associated with a decrease in insulin sensitivity and subsequently impaired glucose utilization [7].

Some studies investigated the role of zinc as a potential adjunct therapy in the management of type 2 diabetes mellitus; the outcomes of such studies were conflicting. Therefore this single blinded non concelaed short randomized trail aimed to evaluate the effect of zinc supplementation on glycemic control in type 2 diabetic patients.

\section{Methods}

Study design and participants

This was a single-blinded randomized placebo controlled clinical trial (participants did not know the type of intervention). The participants consisted of 200 patients with type 2 diabetes on oral hypoglycemic drugs only attending the family medicine outpatient clinics, in Suez Canal University, Ismailia, Egypt. This study was was carried between April 2019 and June 2019.

All patients of the study given their written consent after conselling them for the aim of the study,and after gaining approval of ethical committee. Inclusion criteria were patients with type 2 diabetes, aged $>18$ years old, attending the clinic for a routine followup visit, on regular use of oral anti-diabetic drugs only, with HbAlc concentrations of 7.5-9.5\%, at baselien who were not enrolled in similar program in the last 6 months, and not taking vitamins or mineral supplements in previous 2 months. Exclusion criteria were severe or uncontrolled cardiovascular disease (defined as a cardiovascular event within the last year), psychiatric disease or cognitive impairment interfering with treatment compliance, pregnancy or lactating women.

\section{Sampling and randomization}

A sample size of 90 subjects was required to detect $0.41 \%$ difference in $\mathrm{HbA1c}$ at a standard deviation of 0.69 [8], with $80 \%$ power and $5 \%$ level of significance. Considering a dropout rate of $10 \%$ the sample size estimated as 45 subjects per group, and we extended it to 100 per group for more rigorous statisctical inferences.

During one month period $\mathrm{HbA1c}$ was requested to all patients with type 2 diabetes mellitus who attended family medicine outpatient clinic of Suez Canal University hospital and fulfill inclusion and exclusion criteria. Patients who had HbA1c values of 7.5-9.5\% were listed in a numerical order and were arranged alphabetically.

Total of 200 particiapnts were randomly assigned to either group using a verified ramdom sampling technique and were blind to the treatment given. The intervention group received oral capsule of zinc sulphate $(25 \mathrm{mg}$ ) daily, the control group was given placebo for 12 weeks in addition to their usual care of oral antidiabetic drugs only. 
Data collection

An initial questionnaire included socioeconomic data as age, sex, address, educational level, occupation, medical history as diabetes duration, drug usage, diabetic complications and adherence to recommended diet was completed from included subjects after running pilot study on 20 patients to test validity of the questionaire.

Patients of both groups were given blindly either $25 \mathrm{mg}$ of zinc sulfate or placebo once daily for a period of 12 weeks, both drugs were identical in formulation, shape, size, weight, texture, and packing. Patients were allowed to ask questions regarding any possible side effects and the degree of compliance was followed at the $4^{\text {th }}, 8^{\text {th }}$ and $12^{\text {th }}$ week from beginning of the study by patient interview and pill counts; those taking 90\% (e.g.25 capsules zinc $\backslash 4$ weeks) of the drugs were considered compliant. Adherence to oral anti-diabetic drugs and healthy diet was assessed by interview at every visit. Two patients (from intervention group) were withdrawn after 8 weeks of the study as their anti-diabetic therapy was changed to insulin. Three patients (from placebo group) were withdrawn after 4 weeks of the study without mentioning causes.

Blood samples were collected from all patients (in both zinc and placebo groups) before starting treatment (baseline sample) and then after 12 weeks of treatment to monitor the change in glycated hemoglobin (HbA1c \%) as an indicator of glycemic control.

\section{Statistical analysis}

Statistical analysis was performed using Statistical Package for the Social Sciences (SPSS V18.0). Numerical values were expressed as mean \pm standard deviation (SD). Continuous variables were compared using the Independent-samples $\mathrm{T}$ test. Chi-Square test was used to compare categorical variables between groups. P value of $<0.05$ was considered statistically significant.

\section{Results}

The results of this study of the effect of oral zinc supplementaion $(25 \mathrm{mg}$ ) on glycemic status of type 2 diabetic patients on oral hypogkycemic drugs, and that was run for 12 weeks as single blinded randomized clinical trial with no statistically significant difference between the two groups, regarding age, residence, duration of illness, BMI, and Hba1c \% at baseline (Table 1), and no statistically difference between the two groups regarding type of treatment, and adherence to treatment (Table 2), after 12 weeks of follow up, there was statistically significant difference in outcome variable, Hba1c \%, (8.03\% Vs 8.30\%) in the intervention and control group respectively, although the difference was not clinically significant.

Multiple regression analysis was done (Table 4) to study different selected variables that was best fitting the regression model (multiple regression coefficient $\mathrm{R}$ value $=0.954$ ) and explains $91 \%$ of variation in the outcome variable The unstandardized coefficient of the Intervention was shown to decrease the Hba1c \% by only less than $0.2 \%(0.17 \%)$, while adherence to treatment unstandardized coefficient decreases hba1c $\%$ by $5 \%$ among other less coefficients.

Out of 200 patients selected at the beginning of the research, 195 patients completed this study (Figure 1). Comparison of the baseline characteristics of both groups revealed no significant differences (Table 1).

The majority of patients in the study groups used combined metformin and sulfonylurea for treatment of their diabetes, most of them were adherent to their oral anti-diabetic drugs $176 \%$ in intervention versus $82.2 \%$ in control group) (Table 2). Regarding adherence to Zinc or placebo after 12 weeks, there was no statistically significant difference between intervention and control group (p-value $=0.756)$.

After 12 weeks of zinc or placebo supplementation, the reduction in the level of $\mathrm{HbA} 1 \mathrm{c}$ in zinc group compared to that in placebo group was significant $(\mathrm{p}=0.008)$ (Table 3 ).

About $84 \%$ of the intervention group had better glycemic control; (decreased in HbA1C compared to baseline, while only $45 \%$ were improved in the control group (Table 4).

After exclusion of confounders, all independent variables coefficients are significantly predicted HBA1c. Unstandardized coefficients $B$ indicates that the intervention, male gender, urban residence, adherence to treatment, and will decrease HBA1c by about $0.17 \%, 0.11 \%, 0.16 \%$, and $0.57 \%$, respectively. Additionally, age and BMI will increase HBA1c by about $0.05 \%$ and $0.13 \%$, respectively.

The multiple correlation coefficient $(\mathrm{R}$ value $=0.976)$ indicates a good level of prediction. The coefficient of determination $\left(\mathrm{R}^{2}\right.$ value 


\begin{tabular}{|c|c|c|c|c|}
\hline \multirow[b]{2}{*}{ Variables } & \multicolumn{2}{|c|}{ Groups } & \multirow{2}{*}{$\begin{array}{c}\text { Test } \\
\text { value }\end{array}$} & \multirow[b]{2}{*}{ p-value } \\
\hline & $\begin{array}{c}\text { Interventional } \\
\quad(n=100)\end{array}$ & $\begin{array}{c}\text { Control } \\
(n=100)\end{array}$ & & \\
\hline Age (years), mean \pm SD & $48.23 \pm 7.57$ & $49.95 \pm 6.85$ & 1.683 & $0.09^{a}$ \\
\hline \multicolumn{5}{|l|}{ Gender, n (\%) } \\
\hline Male & $38(38 \%)$ & $45(45 \%)$ & \multirow[t]{2}{*}{1.009} & \multirow[t]{2}{*}{$0.34^{\mathrm{b}}$} \\
\hline Female & $62(62 \%)$ & $55(55 \%)$ & & \\
\hline Duration of diabetes (years) & $4 \pm 1.66$ & $4.07 \pm 1.69$ & 0.295 & $0.768^{\mathrm{a}}$ \\
\hline \multicolumn{3}{|l|}{ Residency, n (\%) } & \multirow{3}{*}{1.085} & \multirow{3}{*}{$0.29^{b}$} \\
\hline Urban & $80(80 \%)$ & $82(82 \%)$ & & \\
\hline Rural & $20(20 \%)$ & $18(18 \%)$ & & \\
\hline BMI (mean \pm SD) & $31.6 \pm 3.19$ & $30.42 \pm 3.03$ & 2.702 & $0.007^{* a}$ \\
\hline $\mathrm{HbA1C}(\%)$, mean $\pm \mathrm{SD}$ & $8.85 \pm 0.59$ & $8.72 \pm 0.62$ & 1.487 & $0.14^{\mathrm{a}}$ \\
\hline
\end{tabular}

Table 1: Baseline Characteristics of Patients in intervention and control Groups ( $\mathrm{n}=200)$. ${ }^{a}$ values are based on Independent-samples ttest. Statistical significance at $\mathrm{p}<0.05$.

${ }^{\mathrm{b}}$ values are based on chi-square test. Statistical significance at $\mathrm{p}<0.05$.

\begin{tabular}{|c|c|c|c|c|}
\hline \multirow[t]{2}{*}{ Variables } & \multicolumn{2}{|c|}{ Groups } & \multirow{2}{*}{$\begin{array}{l}\text { Test } \\
\text { value }\end{array}$} & \multirow{2}{*}{$\begin{array}{c}\text { p- } \\
\text { value }\end{array}$} \\
\hline & $\begin{array}{l}\text { Interventional } \\
\qquad(n=100)\end{array}$ & $\begin{array}{l}\text { Control } \\
(n=100)\end{array}$ & & \\
\hline $\begin{array}{l}\text { Type of oral } \\
\text { hypoglycemic } \\
\text { drugs, n (\%) }\end{array}$ & & & & \\
\hline Metformin & 19 (19\%) & $18(18 \%)$ & 2.111 & $0.35^{b}$ \\
\hline Sulfonylurea & 27 (27\%) & $19(19 \%)$ & & \\
\hline $\begin{array}{l}\text { Combined } \\
\text { Metformin and } \\
\text { Sulfonylurea }\end{array}$ & $54(54 \%)$ & $63(63 \%)$ & & \\
\hline $\begin{array}{c}\text { Adherence to } \\
\text { oral anti-diabetic } \\
\text { drugs, n (\%) }\end{array}$ & & & & \\
\hline Adherent & $76(76 \%)$ & $82(82 \%)$ & 1.085 & $0.30^{\mathrm{b}}$ \\
\hline Non-adherent & $24(24 \%)$ & $18(18 \%)$ & & \\
\hline
\end{tabular}

Table 2: Type of oral anti- diabetic drugs and adherence to them in intervention and control groups $(n=200)$.

${ }^{\mathrm{b}}$ values are based on chi-square test.

Statistical significance at $\mathrm{p}<0.05$.

$=0.953$ ) that shows the independent predictors to explain $95.37 \%$ of the variability of the dependent variable (baseline HBA1c). Ad-

\begin{tabular}{|c|c|c|c|c|}
\hline \multirow{2}{*}{ Variable } & \multicolumn{2}{|c|}{ Groups } & \multirow{2}{*}{ Test } & p-value \\
\cline { 2 - 3 } & $\begin{array}{c}\text { Interventional } \\
\text { value }\end{array}$ & $\begin{array}{c}\text { Control } \\
\text { (n= 98) }\end{array}$ & & \\
\hline HbA1C(\%) & $8.03 \pm 0.69$ & $\begin{array}{c}8.30 \pm \\
0.73\end{array}$ & 2.66 & $0.008^{* a}$ \\
& & & \\
\hline
\end{tabular}

Table 3: Comparison of HbA1c after Treatment with Zinc or Placebo in type 2 diabetic patients.

*Statistically significant.

${ }^{a}$ values are based on Independent-samples ttest. Statistical significance at $\mathrm{P}<0.05$.

justed $\mathrm{R}$ square (Adj. $\mathrm{R}^{2}$ value $=0.950$ ) accurately reports that the regression model with chosen as independent input variables that explain the output variable (baseline HBA1c). Durbin-Watson test suggests that the observations are independent and not autocorrelated.

After exclusion of confounders, all independent variables coefficients significantly predicted HBA1c. Unstandardized coefficients $B$ indicates that the intervention, male gender, urban residence, adherence to treatment, and will decrease HBA1c by about $0.17 \%$, $0.11 \%, 0.16 \%$, and $0.57 \%$, respectively. Additionally, age and BMI will increase HBA1c by about $0.05 \%$ and $0.13 \%$, respectively. 


\begin{tabular}{|c|c|c|c|c|c|c|c|c|}
\hline \multicolumn{9}{|c|}{ Coefficients a $^{\text {a }}$} \\
\hline \multicolumn{2}{|c|}{ Model } & \multicolumn{2}{|c|}{$\begin{array}{c}\text { Unstandardized } \\
\text { Coefficients }\end{array}$} & \multirow[t]{2}{*}{$\begin{array}{l}\text { Standardized } \\
\text { Coefficients }\end{array}$} & \multirow[t]{2}{*}{$\mathbf{T}$} & \multirow{2}{*}{$\begin{array}{l}\text { p-value } \\
\text { Lower } \\
\text { Bound }\end{array}$} & \multicolumn{2}{|c|}{$\begin{array}{c}\text { 95.0\% Confidence } \\
\text { Interval for B } \\
\end{array}$} \\
\hline & B & $\begin{array}{l}\text { Std. } \\
\text { Error }\end{array}$ & Beta & & & & $\begin{array}{l}\text { Upper } \\
\text { Bound }\end{array}$ & \\
\hline \multirow[t]{7}{*}{1} & $\begin{array}{l}\text { (Con- } \\
\text { stant) }\end{array}$ & 2.049 & .214 & & 9.597 & $<0.0001$ & 1.628 & 2.470 \\
\hline & $\begin{array}{c}\text { Inter- } \\
\text { vention }\end{array}$ & -0.174 & .032 & -.129 & -5.509 & $<0.0001$ & -.236 & -.112 \\
\hline & Age & 0.047 & .003 & .504 & 16.672 & $<0.0001$ & .041 & .053 \\
\hline & Gender & -0.110 & .035 & -.080 & -3.145 & 0.002 & -.178 & -.041 \\
\hline & $\begin{array}{l}\text { Resi- } \\
\text { dence }\end{array}$ & -0.159 & .051 & -.092 & -3.093 & 0.002 & -.260 & -.058 \\
\hline & $\begin{array}{c}\text { Adhere } \\
\text { to treat- } \\
\text { ment }\end{array}$ & -0.569 & .062 & -.288 & 9.206 & $<0.0001$ & .447 & .691 \\
\hline & BMI & 0.128 & .008 & .619 & 16.253 & $<0.0001$ & .113 & .144 \\
\hline
\end{tabular}

Table 4: Multiple regression analysis of variables preficting change in outcome variable after the intervention

After exclusion of age and comorbidities, all independent variables coefficients significantly predicted baseline HBA1c. Unstandardized coefficients B indicates that the intervention, residence 2 , higher education, and adherence to diet will decrease HBA1c by about $0.08 \%, 3.3 \%, 1.30 \%$, and $0.29 \%$, respectively. Additionally, female gender, employment, longer DM duration, poor adherence to treatment and higher baseline BMI will increase HBA1c by about 7.48\%, 3.84\%, 1.14\%, $1.20 \%$, and $0.17 \%$, respectively.

\begin{tabular}{|c|c|c|c|c|}
\hline \multirow{2}{*}{ Variable } & \multicolumn{2}{|c|}{ Groups } & \multirow{2}{*}{ Test } & value \\
\cline { 2 - 4 } & Intervention & Control & 2.702 & $0.007 * \mathrm{a}$ \\
\hline BMI (mean \pm SD) & $31.60 \pm 3.19$ & $30.42 \pm 3.03$ \\
$(\mathrm{n}=100)$ & 1.806 & 0.032 \\
at base line & $(\mathrm{n}=100)$ & $30.15 \pm 3.061$ \\
$(\mathrm{n}=97)$ & & \\
\hline BMI (mean \pm SD) & $\begin{array}{c}30.98 \pm 3.412 \\
\text { after 12 weeks }\end{array}$ & $(\mathrm{n}=98)$ & & \\
\hline
\end{tabular}

Table 5: Comparison of BMI at base line and after Zinc supplementation or Placebo for 12 weeks in type 2 diabetic patients. ${ }^{\mathrm{a}}$ values are based on Independent-samples t test. Statistical significance at $\mathrm{P}<0.05$.

Body mass index comparison at baseline showed statistically significant difference between the intervention group (31.6 \pm $3.19)$ and placebo group $(30.42 \pm 3.03)(p=0.007)$. Although both groups achieved some reduction in BMI after 12 weeks of zinc orplacebo supplementation $(30.98 \pm 3.41$ and $30.15 \pm 3.061$ in in- tervention and placebo group respectively), the change in BMI in zinc group compared to that in placebo group wasn 't statistically significant ( $p=0.0 .032$ ) (Table 5). The results of this study that was done to study the effect of oral zinc supplementation (25mg) on glycemic status of type 2 diabetic patients on oral hypogkycemic 
drugs, and that was run for 12 weeks as single blinded randomized clinical trial with no statistically significant difference between the two groups, regarding age, residence, duration of illness, BMI, and Hba1c\% at baseline (Table 1), and also no statistically significant difference between the two groups regarding type of treatment, and adherence to treatment (Table 2), after 12 weeks of follow up, there was statistically significant difference in outcome variable, $\mathrm{Hba1c} \%$, (8.03\% Vs 8.30\%) in the intervention and control group respectively, although the difference was not clinically significant.

Multiple regression analysis was done (Table 4) to study different selected variables that was best fitting the regression model (multiple regression coefficient $\mathrm{R}$ value $=0.954$ ) and explains $91 \%$ of variation of the outcome variable The unstandardized coefficient of the Intervention was shown to decrease the Hba1c \% by only less than $0.2 \%(0.17 \%)$, while adherence to treatment unstandardized coefficient decreases HbA1c \% by .5\% among other less coefficients.

\section{Discussion}

The current study demonstrated that zinc supplementation in a dose of $25 \mathrm{mg} /$ day orally for 12 weeks significantly decreases HbA1c in type 2 DM patients. These results were similar to the results of previous study stated that $\mathrm{HbA} 1 \mathrm{c}$ was reduced significantly from $8 \pm 1.4$ to $7.2 \pm 1.4$ ( $\mathrm{p}=0.04)$ after zinc sulphate consumption for 12 weeks [9].

Also there is agreement with another study that demonstrated a significant decrease in $\operatorname{HbA1C}(\mathrm{p}=0.04)$ with zinc sulfate supplementation for 12 weeks. Patients received randomly either $660 \mathrm{mg}$ zinc sulfate or placebo. The mean HbA1C decreased from 8.13+2.03 to $7.35 \pm 1.62$ after zinc treatment. The mean of HbA1c in the placebo group decreased from $7.53 \pm 0.71$ to $7.46 \pm 0.73$ [10].

Similarly; another study in India reported that adding $50 \mathrm{mg}$ elemental zinc as zinc sulphate to oral anti-diabetic drugs for 12 weeks decreased HbA1c significantly ( $p=0.0001)$. HbA1C decreased from $8.35 \pm 0.87$ to $6.91 \pm 0.67[11]$.

Also another study conducted in Iraq reported that the mean $\mathrm{HbA} 1 \mathrm{c} \%$ concentration of the zinc group decreased significantly after 12 weeks of supplementation with oral zinc in the form of zinc sulfate (30 mg of elemental zinc cap/day), while no significant changes were found in the mean $\mathrm{HbA} 1 \mathrm{c} \%$ of the control group [12]. These results were also similar to the results of our study.

Additionally in a comprehensive systematic review and meta analysis of the studies evaluating the effects of oral Zinc supplementation in patients with diabetes mellitus, researchers summarized the data from 25 studies, involving a total of 1,362 patients and they found that Zinc supplementation causes significant reduction in FBG, PPBG and HbA1c in patients with type-2 diabetes as their results showed that post-supplementation $\mathrm{HbA1c}$ values were significantly reduced in the Zinc treated groups compared with controls. The pooled reduction of $\mathrm{HbA} 1 \mathrm{c}$ was close to $0.6 \%$, a magnitude that is clinically significant [13]. These results were compatible with the findings of the current study.

The beneficial effect of zinc supplementation in type 2 diabetes may be explained by several molecular mechanisms which are believed to be involved in the regulation of blood glucose levels following Zinc supplementation. In a study conducted on mice, it reveled the insulin mimetic and hypoglycemic properties shown by Zinc divalent metal cation $\left(\mathrm{Zn}^{+2}\right)$ complexes [14]. The protein tyrosine phosphatase 1B (PTP 1B), a key regulator of the phosphorylation state of the insulin receptor is known to be a target of Zinc ions [15]. Also studies have shown that Zinc may play a role in improving peripheral insulin sensitivity, as it can potentiate insulin-stimulated glucose transport [16]. Zinc acts as insulin mimetic by activating cell signaling pathways such as tyrosine, PRASA40,P38, SHP-2, Akt, ERK1/2, GSK-3B in both human and mouse skeletal cells.

In contrary to the results of the current research, a study in Saudi Arabia stated that while $\mathrm{HbA1c} \%$ was reduced significantly in zinc group ( $\mathrm{p}<0.001)$, it remained unaltered in placebo group $(p>0.05)$. The reduction in the level of HbA1c in zinc group compared to placebo group was not sataistically significant $(p>0.05)$ [17]. The discrepancy of their results and the current study may be explained on the basis that they used zinc for shorter duration (8 weeks) compared to 12 weeks in our study.

In contrast to our findings, study in Korea stated that HbA1c concentration of diabetic patients did not change significantly after using $50 \mathrm{mg}$ zinc gluconate daily for 4 weeks. The mean of HbA1C was $7.69 \pm 1.19 \mathrm{mg} / \mathrm{dl}$ for the zinc group compared to $8.16 \pm 0.78$ $\mathrm{mg} / \mathrm{dl}$ for the placebo group $(\mathrm{p}=0.076)$ [18]. The discrepancy of 
their results and the current study results are expected as HbA1c reflects 2-3 months of glycemic control.

While another study in Tunisia stated that zinc supplementation didn 't significantly alter HbA1c in a study done on 56 diabetic patients with $\mathrm{HbA1c}>7.5 \%$. They were supplemented with $30 \mathrm{mg}$ zinc gluconate/day for 6 months [19]. The discrepancy between their results and the current study may be due to different zinc preparation, different dosing and different intervention trials time period.

In Chile, it was reported that 1-year of intervention with $30 \mathrm{mg} /$ day zinc supplementation has no significant change on HbA1c; baseline $\mathrm{HbA} 1 \mathrm{c}$ was $6.3 \%, 6.2 \%$ for the placebo group and intervention group respectively. HbA1c after intervention was $6.6 \%$, $6.9 \%$ for the placebo group and intervention group respectively ( $\mathrm{p}$ $=0.419$ ) [20]. These results were not similar to results of our study as glycemic level of this study population was controlled this may be the cause of discrepancy of the results.

Furthermore, as the magnitude of any reduction in $\mathrm{HbA} 1 \mathrm{c}$ is dependent upon several factors such as; baseline HbA1C, background therapy and endogenous -cell function which may explain the discrepancy between the results of the current study and the previous mentioned studies [17-21]. The results of multiple regression analysis showed that the model is the best for predicting change in the outcome variables, and the effect of intervention is only explaining less than $0.2 \%(0.174 \%)$, while the adherence to treatment explain nearly $0.6 \%$ of in decrease of outcome ( $\mathrm{HbAc} \%$ ) Based on these findings, it is suggested that adherence to treatment is a more powerful predictor of decrease in $\mathrm{Hba} 1 \mathrm{c} \%$, and zinc alone is not recommended as an intervention that could help improve glycemic status, although the difference in Hba1c \% was statistically significant (Table 3), but not clinically significant and can not explain the variation in outcome variable as shown in multiple regression analysis These results contradict with findings in other studies, and more large multicenters double-blinded randomized clinically controlled trials are needed that involve larger sample sizes at different clinical settings for longer periods of follow up.

\section{Limitations of the Study}

The current study was single center study, which may reduce its generalizability by decreasing its external validity. It was con- cluded that Zinc may have supplementary benefits with the routine management of type 2 diabetes, however further studies on zinc supplementation using different doses, durations, and in more than one center are needed to reinforce present findings.

\section{Conclusion}

The results of current study showed that oral zinc supplementation has a beneficial effect on glycemic control in type 2 diabetic patients when added to other routine management.

\section{Conflict of Interest}

The authors declare that they have no conflict of interest.

\section{Ethical Approval}

All procedures performed in the study were in accordance with the ethical standards of the research ethics committee of Faculty of Medicine Suez Canal University, approval number (2845\#) in 20/7/2016, and with the 1964 Helsinki declaration and its later amendments.

\section{Informed Consent}

Informed consent was obtained from all individual participants included in the study.

\section{Registration Number}

PACTR202005906229512.

\section{Availability of Data and Materials}

The corresponding author will make available data in this study upon reasonable request.

\section{Funding}

No funding for this research was received.

\section{Authors' Contributions}

Study concept and design: WHF, RHE, and FAE. Acquisition, analysis, and interpretation of the data: All authors. Drafting of the manuscript: WHF. Revision of the manuscript: All authors. Statistical analysis: SAM and WHF. Administrative and technical support: WHF, RH, FAS, and MK HAS and IDI made the final manuscript. The authors have read and approved the manuscript. 
All authors contributed substantially to this work. Conceptualization and proposal writing was done by OE and 00. UA and AA supervised data collection. $\mathrm{KN}$ and AL managed the data and wrote the initial manuscript. OE and 00 provided first revision while UA, AA, HS and ID did second revision and made the final version of the manuscript for publishing. All authors have read and approved the manuscript.

\section{Acknowledgments}

The authors would like to thank all patients and care givers who participated in the completion of this work. Also, we extend our thanks and appreciation to staff members, nurses at the family medicine outpatient clinic at Suez Canal University who actively contributed to this work.

\section{Bibliography}

1. Zaccardi F., et al. "Pathophysiology of type 1 and type 2 diabetes mellitus: a 90-year perspective". Postgraduate Medical Journal 92.1084 (2016): 63-69.

2. International Diabetes Federation. "IDF Diabetes Atlas, $8^{\text {th }}$ ed". Brussels, Belgium: International Diabetes Federation (2017).

3. International Diabetes Federation. "IDF Diabetes Atlas. $6^{\text {th }}$ ed" (2013).

4. Jansen J., et al. "Zinc and diabetes--clinical links and molecular mechanisms". Journal of Nutritional Biochemistry 20.6 (2009): 399-417.

5. Fukunaka A and Fujitani Y. "Role of Zinc Homeostasis in the Pathogenesis of Diabetes and Obesity". International Journal of Molecular Sciences 19.2 (2018): 476.

6. Sladek R., et al. "A genome-wide association study identifies novel risk loci for type 2 diabetes". Nature 445 (2007): 881885.

7. Perez A., et al. "Association between zinc nutritional status and glycemic control in individuals with well-controlled type2 diabetes". Journal of Trace Elements in Medicine and Biology 50 (2018): 560-565.

8. Sakpal TV. "Sample size estimation in clinical trial". Perspectives in Clinical Research 1.2 (2010): 67-69.
9. Parham M., et al. "Effect of zinc supplementation on microalbuminuria in patients with type 2 diabetes: a double blind, randomized, placebo-controlled, cross-over trial". Review of Diabetic Studies 5.2 (2008): 102-109.

10. Afkhami-Ardekani M., et al. "Effect of zinc sulfate supplementation on lipid and glucose in type 2 diabetic patients". Pakistan Journal of Nutrition 7.4 (2008): 550-553.

11. Khan MI., et al. "Effect of high-dose zinc supplementation with oral hypoglycemic agents on glycemic control and inflammation in type-2 diabetic nephropathy patients". Journal of Natural Science, Biology, and Medicine 4.2 (2013): 336-340.

12. Al-Maroof RA and Al-Sharbatti SS. "Serum zinc levels in diabetic patients and effect of zinc supplementation on glycemic control of type 2 diabetics". Saudi Medical Journal 27.3 (2006): 344-350.

13. Jayawardena R., et al. "Effects of zinc supplementation on diabetes mellitus: a systematic review and meta-analysis". Diabetology and Metabolic Syndrome 4.1 (2012): 13.

14. Yoshikawa Y., et al. "Insulinomimetic bis (maltolato) zinc (II) complex: blood glucose normalizing effect in KK-A (y) mice with type 2 diabetes mellitus". Biochemical and Biophysical Research Communications 281 (2001): 1190-1193.

15. Haase $\mathrm{H}$ and Maret W. "Protein tyrosine phosphatases as targets of the combined insulinomimetic effects of zinc and oxidants". Biometals 18.4 (2005): 333-338.

16. Tang $X$ and Shay NF. "Zinc has an insulin-like effect on glucose transport mediated by phosphoinositol-3-kinase and Akt in 3T3-L1 fibroblasts and adipocytes". Journal of Nutrition 131.5 (2001): 1414-1420.

17. El-Ashmony SM., et al. "Effect of zinc supplementation on Glycemic control, lipid profile and renal functions in patients with type 2 diabetics: a single blinded, randomized, placebocontrolled trial". Journal of Biology, Agriculture and Healthcare 2 (2012): 33-41.

18. Oh HM and Yoon JS. "Glycemic control of type 2 diabetic patients after short-term zinc supplementation". Nutrition Research and Practice 2.4 (2008): 283-288.

Citation: Almass Hassan, Maged Khattab, Abdelrauof El Deib, Hind Salama, Mohamed Mohamed Hassan Shora and Ismail Dahshan. "Impact of Oral Zinc Supplementation on Glycemic Control in Type 2 Diabetic Patients: Single-blinded Randomized Controlled Trial". Acta Scientific Medical Sciences 6.1 (2022): 217-225. 
19. Roussel AM., et al. "Antioxidant effects of zinc supplementation in Tunisians with type 2 diabetes mellitus". Journal of the American College of Nutrition 22.4 (2003): 316-321.

20. Pérez A., et al. "Zinc Supplementation Does Not Affect Glucagon Response to Intravenous Glucose and Insulin Infusion in Patients with Well-Controlled Type 2 Diabetes". Biological Trace Element Research 185.2 (2018): 255-261.

21. Norouzi S., et al. "Zinc stimulates glucose oxidation and glycemic control by modulating the insulin signaling pathway in human and mouse skeletal muscle cell lines". PLOS ONE 13.1 (2018): e0191727.

\section{Assets from publication with us}

- Prompt Acknowledgement after receiving the article

- Thorough Double blinded peer review

- Rapid Publication

- Issue of Publication Certificate

- High visibility of your Published work

Website: www.actascientific.com/ Submit Article: www.actascientific.com/submission.php Email us: editor@actascientific.com Contact us: +919182824667 